\title{
LICENCIAS DE MARCA: LA ESTRATEGIA GANADORA
}

\author{
Víctor Magariño Peñalba ${ }^{1}$ \\ Universidad Carlos III de Madrid \\ https://doi.org/10.17979/redma.2010.01.05.4711
}

\section{RESUMEN}

Cuando una compañía no goza del privilegio de estar en posesión de una marca conocida se le presentan básicamente tres opciones:

a. Generar notoriedad de marca.

b. Comprar una marca conocida.

c. Tomar prestada una marca conocida.

El artículo analiza cada una de las opciones y señala que estamos asistiendo a un auge en el sector de la licencia.

Palabras clave: estrategias, marcas, licencias

\section{ABSTRACT}

TRADEMARK LICENSES: THE WINNER STRATEGY

When a company does not have the privilege of possessing a well known trademark, then has basically three options:

a. Generate the notoriety of the trademark

\footnotetext{
${ }^{1}$ Licenciado en Derecho por el CEU San Pablo y MBA por la Escuela de Negocios (ESDEN) Director de Ventas Globales de Frankford Candy \& Chocolate Co.

Profesor de Gestión Internacional de la Empresa en la Universidad Carlos III de Madrid

REDMARKA UIMA-Universidad de A Coruña - CIECID

Año 2, Número 5, (2010), pp.3-9

http://www.redmarka.org/ ISSN 1852-2300
} 
Licencias de marca: la estrategia ganadora

b. Buy a known trademark

c. Borrow a known trademark

The article analyzes each of the options and concludes that we assist a boom in the license sector.

Keywords: strategy, trademarks, licenses 
Una empresa de reciente creación comparte un hándicap similar a aquella que, a pesar de llevar varios años en el mercado, aún no ha conseguido que su marca sea reconocida y valorada por su público objetivo. Su producto no se encuentra diferenciado ni suficientemente apreciado. En estos casos, cuando una compañía no goza del privilegio de estar en posesión de una marca conocida se le presentan básicamente tres opciones:

d. Generar notoriedad de marca.

e. Comprar una marca conocida.

f. Tomar prestada una marca conocida.

Cualquiera de las dos primeras opciones implica unos niveles de inversión considerables. En el primer caso estamos hablando básicamente de inversiones masivas en publicidad y por supuesto un periodo razonablemente largo de tiempo. Por ejemplo se calcula que hacen falta unos 17 millones de dólares para conseguir cierta notoriedad de marca en China y a esto hay que añadir unos dos millones más al año para sostener dicha notoriedad.

En el segundo caso se trata obviamente de capacidad de compra y de cómo de grande sea el cheque que ponemos delante de la empresa poseedora del valioso activo marquista.

La tercera alternativa se presenta como más al alcance de empresas de tamaño mediano e incluso pequeño y con recursos limitados. En realidad se trata de una forma de outsourcing, tan de moda en nuestros tiempos.

Veamos un sencillo ejemplo. Mantenemos un deseo irrefrenable de conducir un Ferrari y sin embargo no disponemos del capital necesario para adquirir uno. ¿Qué podemos hacer? Fácil, podemos alquilar uno durante un día o una semana por un 
precio que con más probabilidad sí alcanzaremos a pagar.

De la misma forma, si una empresa carece de los recursos necesarios par invertir en generar notoriedad de sus marcas y tampoco dispone de la capacidad financiera para adquirir marcas conocidas, siempre puede acudir al mercado de alquiler de marcas, esto es, alcanzar acuerdos de licencia de marca o "licensing", versión corta en inglés.

Echemos un rápido vistazo a los lineales de los supermercados. Edredones y sábanas con la imagen de Spiderman o Batman, lamparitas infantiles con Winnie the Pooh, caramelos envasados en un corazón con logo Barbie, galletas de los Simpson, la lista es interminable. Pero no solo en el segmento infantil. Ropa sport de alta gama con exclusivas marcas del juego de polo, todo tipo de complementos (gafas de sol, relojes, paraguas, etc.) con logos de marcas de automóviles de lujo.

Afortunadamente para las empresas locales de tamaño mediano, la política de una gran mayoría de las grandes multinacionales de productos de gran consumo favorece la aparición de suculentos nichos de mercado que se generan de la mano de acuerdos de licencias. Ser capaz de identificarlos y aprovecharlos no es tarea que requiera excesivos recursos económicos, ni tan si quiera disponer de grandes talentos o estrategias complejas.

Una empresa norteamericana fabricante de productos de chocolate estacionales de gran tradición fue capaz de transformar casi por completo su modelo de negocio y en apenas dos años convertirse en líder del mercado de confitería estacional en EEUU, con crecimientos anuales sostenidos que triplicaban los del mercado. ¿Porqué ellos y no otros? ¿Qué impidió a sus competidores identificar y explotar la gallina de los huevos de oro?

Por un lado tenemos los grandes fabricantes multinacionales, Nestlé, Cadbury, Hershey's, etc. Todos ellos con un denominador común: interés en desarrollar 
globalmente sus propias marcas. Y, por oposición, cero interés en gastar recursos en exhibir y por lo tanto aumentar la notoriedad de las marcas de los demás. La estrategia para estas grandes empresas es clara, no se trata sólo de vender más y ganar cuota de mercado frente a los competidores, sino de construir más y mejores activos marquistas que aporten valor a la compañía (y en última instancia al venerado accionista).

Son por tanto las empresas digamos de segunda línea (no multinacionales) las más indicadas para recurrir al recurso de la licencia de marca. En algunos sectores parece una estrategia obvia. Juntar conocidas propiedades infantiles (Cars, Barbie, Princesas, etc.) con cualquier producto de gran consumo infantil parece una forma clara y rápida de alcanzar el éxito. Juguetes por supuesto, pero también: caramelos y chocolates, alimentación infantil en general, ropa, calzado, complementos, productos de aseo infantil, ropa de cama, el listado es amplio y en buena medida está aún por explotar.

El hecho de que las propias multinacionales se auto excluyan con frecuencia de este tipo de acuerdos de licencias de marca para sus productos hace crecer el número de rivales en la pelea y la convierte casi siempre en una interesante batalla de tipo local.

Veamos qué busca principalmente el licenciatario en un acuerdo de licencia, pongamos por ejemplo una gran compañía de entretenimiento como Disney:

1. Nivel de compromiso con la marca o marcas licenciadas (en estos casos se habla de propiedades o "properties"), que se traduce en un mínimo garantizado.

2. Porcentaje sobre las ventas, conocido como royalty.

3. Nivel de distribución, que se traduce en la mejor oferta para alcanzar el mayor número de puntos de venta.

4. Limitar el periodo de compromiso, lo cual le permitirá salir del acuerdo en 
un plazo razonable en el caso de no sentirse satisfecho con el resultado del mismo, o de recibir una propuesta más atractiva.

5. Garantizar determinados estándares de calidad en los productos ofrecidos bajo su marca mediante un sistema de auditorías, que aumenta considerablemente su complejidad cuando se trata de productos de alimentación.

Últimamente también se viene observando un incremento de la preocupación por ofrecer productos considerados como "sanos" (o que al menos aparenten serlo), no obstante, esta es una tendencia que, aunque en crecimiento, queda por el momento eclipsada por el resto de las consideraciones arriba descritas.

¿Qué busca el licenciado? Rápido y simple: disponer de inmediato de una marca conocida, lo cual le permitirá:

1. Incrementar significativamente el interés de los distribuidores en su producto y por lo tanto su poder de negociación.

2. Aumentar sus ventas.

3. Situarse rápidamente en una posición clara de ventaja sobre sus competidores.

En un escenario de alta rivalidad y competencia por el espacio en las estanterías en donde con frecuencia sólo hay lugar para una o dos marcas líderes junto a la marca de la distribución, la posibilidad de disponer de un producto conocido y por tanto deseado en un corto espacio de tiempo es tremendamente atractiva.

Es por ello que sin duda estamos asistiendo a un auge en el sector de la licencia. Sin embargo las posibilidades son realmente tan extraordinarias que más empresas deberían orientar sus departamentos de marketing en esta dirección antes de que sus competidores sean capaces de identificar y alcanzar tan suculenta ventaja competitiva. Quieren un ejemplo curioso y reciente: New 
Scotland Yard ¿les suena? acaba de licenciar su marca en un amplio espectro de categorías.

\section{Para citar este artículo:}

Magariño Peñalba, Víctor (17-12-2010). LICENCIAS DE MARCA: LA ESTRATEGIA GANADORA.

REDMARKA - CIECID - Unidad de Investigación en Marketing Aplicado-Universidad de A Coruña

Año II, Número 5, pp. 3-9

ISSN $1852-2300$

URL del Documento : cienciared.com.ar/ra/doc.php?n=1411

URL de la Revista : cienciared.com.ar/ra/revista.php?wid=39 